\title{
Effect of Water Potential on Conidial Germination and Antagonism of Ulocladium atrum Against Botrytis cinerea
}

\author{
J. Köhl and W. M. L. Molhoek
}

Plant Research International, P.O. Box 16, 6700 AA Wageningen, the Netherlands. Accepted for publication 19 January 2001.

\section{ABSTRACT}

Köhl, J., and Molhoek, W. M. L. 2001. Effect of water potential on conidial germination and antagonism of Ulocladium atrum against Botrytis cinerea. Phytopathology 91:485-491.

The saprophytic fungus Ulocladium atrum was selected for its ability to competitively exclude Botrytis spp. from aboveground necrotic plant tissues which can play a crucial role in the epidemiology of diseases caused by necrotrophic Botrytis spp. Fungal growth in necrotic aboveground tissues can be hampered by fluctuating water availability. Adaptation to these adverse conditions is a key factor for the successful establishment of an antagonist population in this niche. Conidia of $U$. atrum germinated at water potentials between -1 and $-7 \mathrm{MPa}$ on water agar. Germinated conidia survived one to three interruptions of moist incubation by periods at -10 or $-42 \mathrm{MPa}$. The speed of germination was significantly slower with interruption of the moist period as compared with the control, which had continuously moist incubation. However, the maximum germination percentage was the same for conidia incubated with or without interruption of the moist incubation. In bioassays with necrotic cyclamen leaves at $-1,-3$, and $-7 \mathrm{MPa}, U$. atrum significantly reduced the sporulation of B. cinerea by more than $80 \%$. The results demonstrate that $U$. atrum tolerates water stress during competitive substrate colonization with $B$. cinerea. The antagonist is, therefore, an attractive candidate for field applications on aboveground tissues.
The saprophytic fungus Ulocladium atrum Preuss was selected as an antagonist against Botrytis spp. $(17,18)$. It competes with the pathogen in its saprophytic stage in necrotic aboveground plant tissues. Such necrotic tissues can play a crucial role in Botrytis epidemics, where they serve as substrate for conidia production (e.g., dead strawberry leaves [4]), or as a bridge allowing the pathogen to attack neighboring healthy tissue (e.g., dead leaves in cyclamen plants [14] and necrotic flower parts in strawberry and grapes $[12,28])$. U. atrum has been used successfully for biological control of B. cinerea under field conditions in grapes (26) and strawberry (13) as well as in greenhouse crops such as cyclamen (14) and tomato (10).

As the niche for the antagonistic interaction, aboveground plant tissues are characterized by variable microclimatic conditions, often adverse for fungal growth. Water availability and temperature can change very rapidly. Data obtained during field experiments during several summers in the Netherlands showed that wetness periods of necrotic leaf tissues frequently occur, but that the duration of wetness periods can vary between a few minutes and more than $24 \mathrm{~h}$. Wetness periods had an average duration of $4.9 \mathrm{~h}$ measured in onion as an open crop and $9.7 \mathrm{~h}$ in lilies as a dense crop (16). To obtain reliable biological control, antagonists must be able to survive and to compete with the pathogen under these conditions.

The antagonist $U$. atrum is effective over a broad range of temperatures (16) and antagonism was found in bioassays conducted with interrupted leaf wetness periods (18). Little information is available in the literature about the fate of germlings of antagonistic fungi in the phyllosphere. The objective of the study was to determine the effect of constant and alternating water potentials on conidia of $U$. atrum during germination. Experiments were

Corresponding author: J. Köhl; E-mail address: j.kohl@plant.wag-ur.nl

Publication no. P-2001-0316-01R

(C) 2001 The American Phytopathological Society carried out under conditions leading to equilibration of the water potential in the growth substrate and the surrounding atmosphere. More complex situations, in which the water potentials of the substrate and the surrounding atmosphere differ (e.g., when a dry necrotic leaf is exposed to a sudden increase of the relative humidity (RH) of the surrounding air), were not considered.

This information will help to better understand the dynamics of antagonist populations under field conditions, which is a prerequisite for the development of reliable application strategies.

\section{MATERIALS AND METHODS}

Conidial suspensions. $U$. atrum (isolate number 385), isolated from necrotic leaf tips of onions (18), and Botrytis cinerea Pers.:Fr. (isolate number 700), isolated from a gerbera flower, were cultured in petri dishes $(90 \mathrm{~mm})$ containing $25 \mathrm{ml}$ of oatmeal agar (20 g of oatmeal, $15 \mathrm{~g}$ of agar, $1,000 \mathrm{ml}$ of tap water) for 28 and 14 days, respectively, at $18^{\circ} \mathrm{C}$ in the dark. To obtain conidial suspensions, cultures were flooded with sterile tap water containing $0.01 \%$ (vol/vol) Tween 80 . After gently rubbing with a rubber spatula, the resulting suspension was filtered through sterile nylon gauze with a mesh of $200 \mu \mathrm{m}$. Concentrations of the conidial suspensions were determined with the aid of a hemacytometer and adjusted with sterile tap water containing $0.01 \%$ Tween 80 to $5 \times 10^{5}$ conidia per ml. Flasks containing the conidial suspensions were kept in ice water and suspensions were used within $1 \mathrm{~h}$.

Conidial germination at different constant and alternating water potentials. Glass slides were covered with a thin layer of water agar (15 $\mathrm{g}$ of agar, 1 liter of tap water) as described by Fokkema (9) and dried in a sterile laminar flow cabinet. Slides were sprayed with a conidial suspension of $U$. atrum $(5 \times$ $10^{5}$ conidia per $\mathrm{ml}$; approximately 800 conidia per $\mathrm{cm}^{2}$ ) and left to dry in the sterile flow cabinet for $30 \mathrm{~min}$. Subsequently, each agar slide was transferred to a moist chamber, consisting of a petri dish (90 mm) containing $15 \mathrm{ml}$ of demineralized water or mixtures of demineralized water and glycerol (6) to obtain, at equilibrium, 
water potentials in the agar layer of $-0.28,-1,-3,-5,-7,-10$, or $-14 \mathrm{MPa}$, corresponding to RHs of 99.8, 99.3, 97.9, 96.4, 95.0, 92.9 , and $90.0 \%$. Glycerol-water solutions were freshly prepared for each experiment. A lid of a smaller petri dish $(60 \mathrm{~mm})$ had been fixed in the center of the petri dish to support the agar slide so that there was no contact between the water-glycerol mixture and the agar layer. Immediately after transfer of the agar slides to the moist chambers, the latter were sealed with Parafilm and incubated at $18 \pm 0.5^{\circ} \mathrm{C}$ in the dark. After the incubation period, fungal growth in the sampled dishes was stopped immediately by adding $1 \mathrm{ml}$ of household ammonia $(4.8 \%$ [wt/wt $\left.] \mathrm{NH}_{4} \mathrm{OH}\right)$ onto a filter paper $(40 \mathrm{~mm})$ placed into the small petri dish and closing the petri dish again. Agar slides were stored at $5^{\circ} \mathrm{C}$ until microscopic examination.

Experiments were carried out with constant or alternating water potentials. In the experiment with incubation at constant water potentials, agar slides were incubated in petri dishes containing water-glycerol mixtures as described above. Incubation periods were, based on results of preliminary experiments, 4, 6, 8, 12, 16, $24,36,48$, and $72 \mathrm{~h}$ for each water potential, except at $-0.28 \mathrm{MPa}$, where the longest incubation period was $24 \mathrm{~h}$, and at -10 and $-14 \mathrm{MPa}$, where incubation periods were 24,48 , and $72 \mathrm{~h}$. For each incubation period at each water potential, three arbitrarily chosen agar slides were sampled. The experiment was repeated.

For experiments with alternating water potentials, agar slides were inoculated and incubated in petri dishes containing waterglycerol mixtures, as described above. Water potentials of the agar layer were changed by rapidly transferring agar slides to petri dishes containing the appropriate glycerol-water mixtures. Conidia on agar slides were incubated under conditions of high water availability at $-1 \mathrm{MPa}$ (equivalent to $99.3 \% \mathrm{RH}$ ) which were interrupted by one period of low water availability at $-10 \mathrm{MPa}$ (equivalent to $92.9 \% \mathrm{RH}$ ). Agar slides were incubated first in petri dishes at $-1 \mathrm{MPa}$ for $0,2,4,6$, or $8 \mathrm{~h}$ and subsequently at $-10 \mathrm{MPa}$ for $24,22,20,18$, or $16 \mathrm{~h}$, respectively. Thereafter, agar slides were transferred again to petri dishes containing glycerolwater mixtures at $-1 \mathrm{MPa}$. In a similar experiment, agar slides were incubated at $-42 \mathrm{MPa}$ (equivalent to $70 \% \mathrm{RH}$ ) during periods of low water availability. Three arbitrarily chosen agar slides were sampled for each treatment (duration of incubation before period of low water availability started) after a total incubation time at high water availability ( $-1 \mathrm{MPa})$ of $0,2,4,6,8,10,12,24$, or $32 \mathrm{~h}$. Additionally, three agar slides of each treatment were always sampled immediately after incubation periods at low water availability. The experiment was repeated for both water potential levels during periods at low water availability.

In another experiment, conidia on agar slides were incubated at high water availability ( $-1 \mathrm{MPa})$ interrupted by two or three periods of low water availability $(-42 \mathrm{MPa})$. The incubation period at $-1 \mathrm{MPa}$ lasted $6 \mathrm{~h}$, followed by a period of $18 \mathrm{~h}$ at $-42 \mathrm{MPa}$. These cycles were repeated two or three times and were then followed by continuous incubation at $-1 \mathrm{MPa}$. Conidia incubated continuously under moist conditions served as the control. For each of the three treatments, three sets of agar slides were incubated, each prepared with a suspension of $U$. atrum conidia obtained from a separate petri dish. Such sets of petri dishes were allocated to three blocks within the incubator. Agar slides prepared for the different sampling times were arranged randomly within each block. One agar slide per block of each for the treatments was sampled after $0,2,4,6,8,10,12$, and $24 \mathrm{~h}$ of incubation at $-1 \mathrm{MPa}$. The next samples were taken after $72 \mathrm{~h}$ for the control treatment; after 36 and $84 \mathrm{~h}$ for the treatment with two dry periods; and after 30, 42, and $90 \mathrm{~h}$ for the treatment with three dry periods. Additionally, three agar slides of each treatment were always sampled immediately after incubation periods at low water availability. The experiment was repeated.

Germination was assessed from 100 arbitrarily chosen conidia per slide stained with cotton blue in lactic acid $(2 \mathrm{ml}$ of lactic acid, $4 \mathrm{ml}$ of glycerol, $2 \mathrm{ml}$ of distilled water, $15 \mathrm{mg}$ of cotton blue) using a microscope $(\times 200$; Axioscope, Zeiss, Oberkochen, Germany). Conidia with germ tubes longer than half of the minimum diameter of a conidium were considered to have germinated. For several treatments, the number of germ tubes of 50 arbitrarily chosen conidia was counted and the length of each germ tube was measured using an interactive digitizer (Minimop, Kontron, Oberkochen, Germany). When more than one germ tube was present the longest was defined as the first and the next longest as the second germ tube.

Antagonism on cyclamen leaves at different water-potentials. Symptomless green leaves were removed from cyclamen plants (approximately 30 weeks old), placed on dry filter paper, and allowed to senesce for 6 weeks at ambient temperature and 50 to $70 \% \mathrm{RH}$. Leaves were rehydrated and cut into pieces of approximately 4 by $4 \mathrm{~mm}$ which were dried between dry filter paper in a plant press to obtain flattened leaf pieces. One hundred dry leaf pieces were weighed, sealed in plastic bags and gamma irradiated (4 Mrad). Fourteen days before the beginning of experiments, sterile water was added to the plastic bag with the leaf pieces and the bags were sealed again and stored for 1 week to allow equilibration of leaf piece water content. To obtain water potentials of approximately $-1,-3$, and $-7 \mathrm{MPa}, 1.5,0.5$, or $0.25 \mathrm{ml}$ of sterile tap water per gram of leaf pieces (dry weight) was added, respectively, according to the relationship between water content and water potential available for dead onion leaves (18).

Moist chambers were prepared consisting of sterile plastic petri dishes $(140 \mathrm{~mm})$ containing $75 \mathrm{ml}$ of water agar with $\mathrm{KCl}$ added to obtain a water potential of the agar of $-1,-3$, and $-7 \mathrm{MPa}(5)$. A sterile glass slide (76 by $26 \mathrm{~mm}$ ) was placed on the agar and separated from the agar by a sterile plastic grid to avoid diffusion of $\mathrm{KCl}$ onto the slide surface. After incubation for 7 days at $20^{\circ} \mathrm{C}$ in wetted plastic bags, leaf pieces were transferred into moist chambers with the corresponding water potential. Ten leaf pieces were placed on the glass slide in each moist chamber, sealed with parafilm, and stored for 7 days at $18^{\circ} \mathrm{C}$ to allow equilibration of the water potentials and obtain a precisely controlled water potential in the leaves (15).

On another set of sterile glass slides, conidial suspensions of $B$. cinerea $\left(1 \times 10^{5}\right.$ and $1 \times 10^{6}$ conidia per $\left.\mathrm{ml}\right)$ or $U$. atrum $(1 \times$ $10^{6}$ conidia per $\mathrm{ml}$ ) were sprayed at a rate of approximately $1 \mu \mathrm{l} / \mathrm{cm}^{2}$ and subsequently allowed to dry in a sterile laminar flow cabinet. The five treatments consisted of spraying each of the three conidial suspensions alone and spraying the conidial suspension of the antagonist followed by spraying conidial suspensions of $B$. cinerea at the two different concentrations. In this case, the second spray was carried out after the first suspensions had been allowed to dry on the slide. The 10 leaf pieces per moist chamber at the different water potentials were transferred rapidly, using sterile forceps, onto glass slides containing dried conidia of the different fungi. To ensure a relatively stable water potential in the leaf pieces during this operation, this was carried out in a glass box ( 30 by 30 by $48 \mathrm{~cm}$ ) with wet filter paper fixed to the walls. Slides with leaf pieces were immediately placed back into the moist chambers and moist chambers were sealed with parafilm. Leaf pieces were then incubated at $18 \pm 0.5^{\circ} \mathrm{C}$ in the dark. Each of the five fungal treatments was carried out for each of the three water potentials on three glass slides in separate moist chambers (replicates). After incubation at $18^{\circ} \mathrm{C}$ in the dark for 14 and 28 days, fungal sporulation on the leaf pieces was assessed using sporulation classes, and a sporulation index (0 to 100) was calculated (14). The experiment was repeated.

Statistics. The data on conidial germination over time were analyzed by fitting the Gompertz curve, an asymmetric logistic curve: $Y=C \times \exp \{-\exp (-B \times[X-M])$, where $Y=$ germination percentage; $X=$ total incubation period in hours at constant water potentials for experiments with continuous incubation at different 
water potentials or moist condition $(-1 \mathrm{MPa})$ for experiments with varying water potentials; and $C, B$, and $M=$ the parameters to be estimated. In the curve, $C=$ upper asymptote (maximum germinated percentage), $B=$ rate of increase in percentage of germinated conidia (slope parameter), and $M=$ point of inflection (time needed to achieve $37 \%$ of the maximum germination percentage). Continuous incubation at -10 and $-14 \mathrm{MPa}$ did not result in germination; therefore, these data were excluded from analyses. During the fitting process, the lower asymptotes were forced to zero as the minimum level of germination percentage. Using the estimates of the parameters in the curve, the expected germination percentage can be calculated.

Curves were fitted to the data for the repeated experiments with constant water potentials, with one interruption of the incubation under moist conditions $(-1 \mathrm{MPa})$ by a dry period $(-10$ or -42 $\mathrm{MPa}$ ) and with multiple interruptions of the moist period. A separate curve was fitted for each treatment of each block (if relevant) in each experiment. The parameters of the fitted Gompertz curves were then analyzed using the original structure of the experimental units (21). Due to the different experimental designs, experiments with continuous incubation under moist conditions or with one interruption of the incubation under moist conditions $(-1$ $\mathrm{MPa}$ ) were analyzed differently from experiments with multiple interruptions of moist periods. The different constant water potentials and the duration of the initial dry period have quantitative treatment levels; therefore, the curve parameters $C, B$, and $M$ were analyzed using linear regression. The experiments with multiple interruptions of the moist period resulted in a total of 18 curves. The treatment effect on the curve parameters $C, B$, and $\mathrm{M}$, was tested in an analysis of variance, taking the blocks and different experiments into account. Significant $F$ tests $(P<0.05)$ were followed by least significant difference (LSD) tests $(\alpha=0.05)$ for testing pairwise differences between treatment means.

Angular transformed data of the repeated experiment on antagonism of $U$. atrum toward $B$. cinerea at different water potentials were combined and analyzed by analysis of variance (ANOVA) followed by LSD tests $(\alpha=0.05)$ for testing pairwise differences between treatment means.

\section{RESULTS}

Conidial germination at constant water potentials. Conidial germination of $U$. atrum was observed between -0.28 and $-7 \mathrm{MPa}$ (Fig. 1), but no germination was observed within $72 \mathrm{~h}$ at -10 and $-14 \mathrm{MPa}$. Gompertz curves fitted to the data had values for an

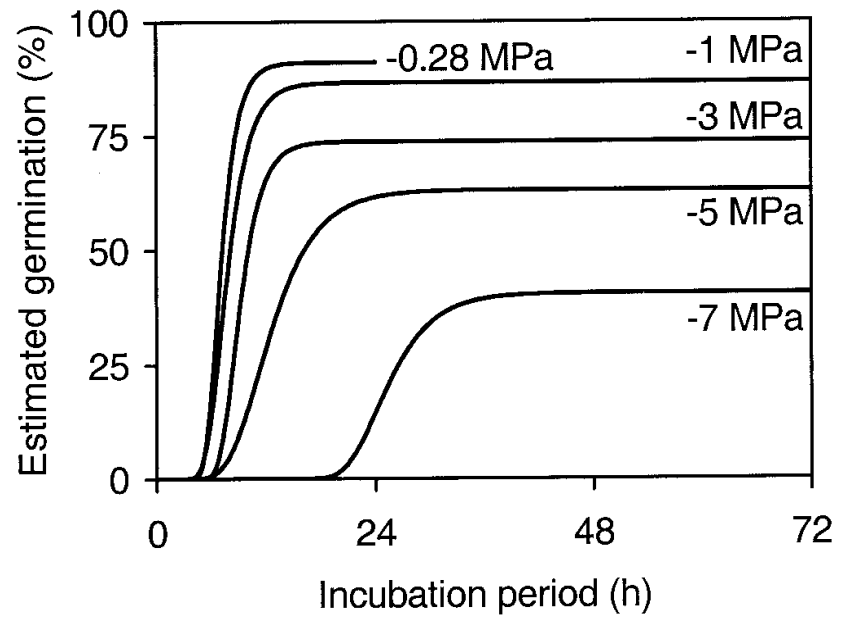

Fig. 1. Estimated germination percentage of conidia of Ulocladium atrum on water agar slides at different water potentials (MPa). Gompertz curves were fitted to data obtained from repeated experiments. Adjusted $R^{2}$ for the different treatments ranged between 0.76 and 0.98 . adjusted $R^{2}$ (given as proportion) ranging between 0.76 and 0.98 . The initial germination process was slower with decreasing water potential. The point of inflection $M$, estimating the time needed to reach $37 \%$ of the maximum germination percentage, significantly $(P<0.001)$ increased with decreasing water potential (Table 1$)$. Conidia needed $6.6 \mathrm{~h}$ at $-0.28 \mathrm{MPa}$ to reach this point but $24 \mathrm{~h}$ at $-7 \mathrm{MPa}$. The speed of germination, as represented by the slope parameter $B$, was affected and significantly $(P=0.003)$ decreased with decreasing water potential. The estimated maximum germination percentage (upper asymptote $C$ ) was high for conidia incubated at -0.28 with $91 \%$ but significantly $(P<0.001)$ decreased with decreasing water potential. At $-7 \mathrm{MPa}$, less than half of the maximum germination percentages were found as compared to -0.28 .

Conidial germination at alternating water potentials. In the first set of experiments, conidia on agar slides were incubated in a moist environment $(-1 \mathrm{MPa})$ and this moist incubation was interrupted once by a period of dry conditions $(-10$ or $-42 \mathrm{MPa})$ at different times during the initial stage of germination between 0 and $8 \mathrm{~h}$. Gompertz curves fitted to the data had adjusted $R^{2}$ ranging between 0.91 and 0.99 for experiments with dry periods at $-10 \mathrm{MPa}$ and between 0.90 and 0.99 for experiments with dry periods at $-42 \mathrm{MPa}$ (Figs. 2 and 3). An exception was the treatment in which the moist incubation of conidia was interrupted after $8 \mathrm{~h}$ with a dry period at $-42 \mathrm{MPa}$ (Fig. 3), for which no

TABLE 1. Parameter estimates of Gompertz curves fitted to the germination percentage of conidia of Ulocladium atrum incubated on agar slides at different water potentials $(\mathrm{MPa})$

\begin{tabular}{lccc}
\hline & \multicolumn{3}{c}{ Gompertz curves parameters $^{\mathrm{y}}$} \\
\cline { 2 - 4 } Water potential & $M$ & 0 & $C$ \\
\hline-0.28 & 6.6 & 0.78 & 91 \\
-1 & 7.0 & 0.60 & 87 \\
-3 & 8.5 & 0.29 & 74 \\
-5 & 11.2 & 0.30 & 63 \\
-7 & 24.0 & & 41 \\
Analysis $^{z}$ & & $0.069( \pm 0.016)$ & $7.200( \pm 1.210)$ \\
Slope & $-2.318( \pm 0.430)$ & 0.003 & $<0.001$ \\
$t$ probability $^{-}$ & $<0.001$ &
\end{tabular}

${ }^{\mathrm{y}}$ Means of two experiments; $M=$ point of inflection, $B=$ slope parameter, and $C=$ upper asymptote.

z Linear regression analysis between Gompertz curve parameters and water potential; slope parameter ( \pm standard error).

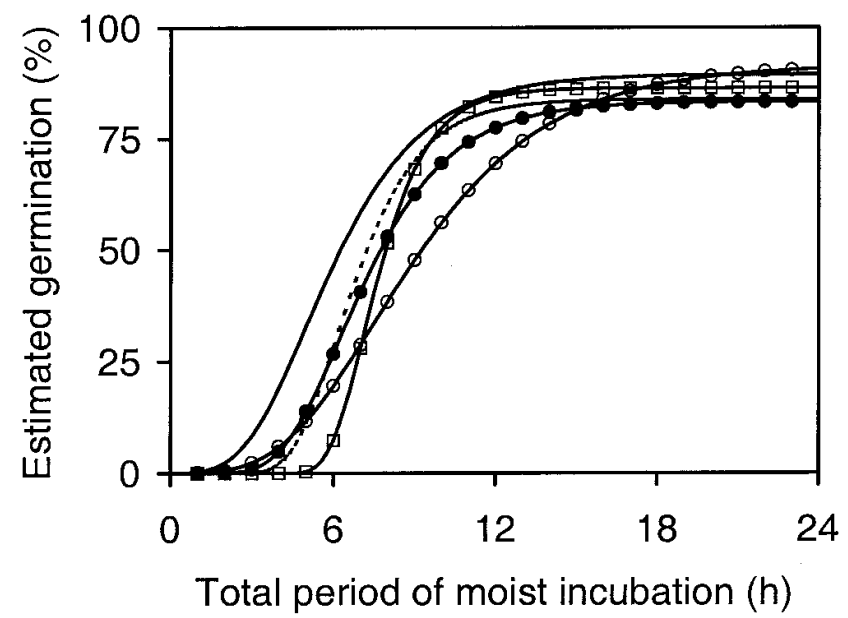

Fig. 2. Estimated germination percentage of conidia of Ulocladium atrum incubated on agar slides under moist conditions (-1 MPa) interrupted by a dry period at $-10 \mathrm{MPa}$ during the initial stage of germination. Initial period of moist incubation was 0 (solid line), 2 (dashed line), $4(\square), 6(\bigcirc)$, or $8 \mathrm{~h}$ (•). Sum of hours of initial moist period and dry period was $24 \mathrm{~h}$. Gompertz curves were fitted to data obtained from repeated experiments. Adjusted $R^{2}$ for the different treatments ranged between 0.91 and 0.99 . 
Gompertz curve was fitted. For this treatment, a lag time of approximately $4 \mathrm{~h}$ was observed for the continuation of the germination process after the dry period.

Values for germination percentages determined at the beginning of a dry period $(-10$ or $-42 \mathrm{MPa})$ and at the end of a dry period (data not shown) did not differ significantly, indicating that the germination process did not continue during dry periods. In the experiment with dry periods at $-10 \mathrm{MPa}$, no statistically significant effects were found attributable to the increase of the duration of the initial moist incubation on the estimated maximum level for the germination percentage $(C)$, ranging between 85 and $91 \%$; the slope parameter $(B)$; and the point of inflection $(M)$ (Table 2). In the experiments with a dry period at $-42 \mathrm{MPa}$, similar results were obtained for parameter $C$, which ranged between 88 and $91 \%$ (Table 3). Values of the point of inflection $(M)$ significantly $(P<0.001)$ increased and the slope parameter $(B)$ significantly $(P=0.021)$ decreased with increasing duration of initial moist incubation. In the treatment with continuously moist conditions, conidia needed $8.1 \mathrm{~h}$ to reach $37 \%$ of the estimated maximum germination percentage. With a dry period, these periods were 1.3 to $4.3 \mathrm{~h}$ longer.

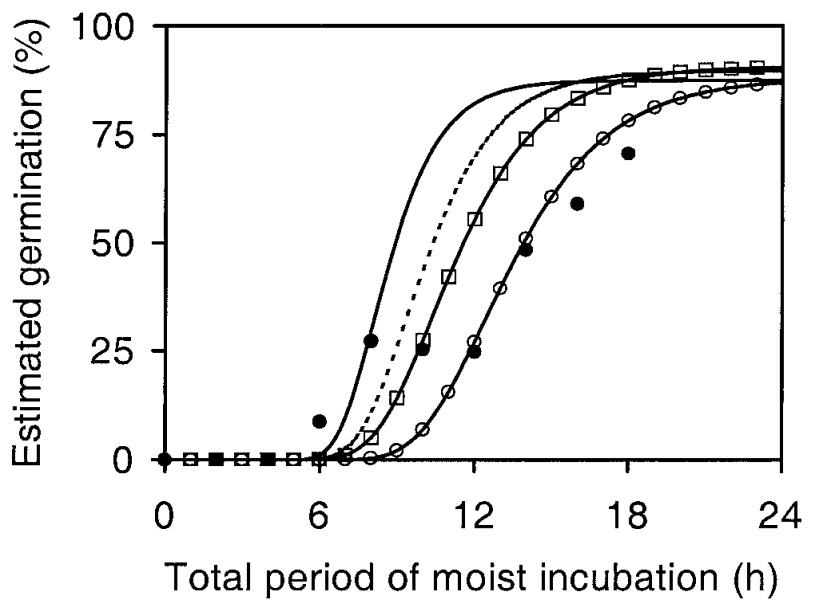

Fig. 3. Estimated germination percentage of conidia of Ulocladium atrum incubated on agar slides under moist conditions ( $-1 \mathrm{MPa}$ ) interrupted by a dry period at $-42 \mathrm{MPa}$ during the initial stage of germination. Initial period

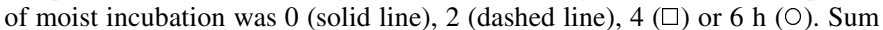
of hours of initial moist period and dry period was $24 \mathrm{~h}$. Gompertz curves were fitted to data obtained from repeated experiments, except for treatment with initial period of moist incubation of $8 \mathrm{~h}$, for which means of observed germination percentage are presented $(\bullet)$. Adjusted $R^{2}$ for the different treatments ranged between 0.90 and 0.99 .

TABLE 2. Parameter estimates of Gompertz curves fitted to the germination percentage of conidia of Ulocladium atrum incubated on agar slides under moist conditions $(-1 \mathrm{MPa})$ interrupted by a dry period at $-10 \mathrm{MPa}$ during the initial stage of germination

\begin{tabular}{lccc}
\hline & \multicolumn{3}{c}{ Gompertz curves parameters $^{\mathrm{x}}$} \\
\cline { 2 - 4 }${\text { Duration }(\mathrm{h})^{\mathrm{y}}}^{\mathrm{n}}$ & $M$ & \multicolumn{1}{c}{$B$} & $C$ \\
\hline 0 & 5.3 & 0.56 & 91 \\
2 & 6.9 & 1.06 & 85 \\
4 & 7.6 & 0.85 & 87 \\
6 & 7.2 & 0.33 & 90 \\
8 & 6.5 & 0.79 & 87 \\
Analysis $^{\mathrm{z}}$ & & & \\
Slope & $0.225( \pm 0.125)$ & $-0.013( \pm 0.058)$ & $-0.114( \pm 0.474)$ \\
$t$ probability & 0.111 & 0.834 & 0.816 \\
\hline
\end{tabular}

${ }^{\mathrm{x}}$ Means of two experiments; $M=$ point of inflection, $B=$ slope parameter, and $C=$ upper asymptote.

${ }^{y}$ Duration of initial moist period; sum of moist plus dry period was $24 \mathrm{~h}$.

${ }^{z}$ Linear regression analysis between Gompertz curve parameters and duration of initial moist incubation; slope parameter ( \pm standard error).
For the control treatment without interruption of moist incubation and the treatment with a dry period $(-42 \mathrm{MPa})$ after $8 \mathrm{~h}$ of incubation under moist conditions, the number of germ tubes and their length was determined after $8 \mathrm{~h}$ and after the maximum germination percentage had been reached after $24 \mathrm{~h}$ for conidia incubated without interruption of the moist period and after $32 \mathrm{~h}$ for conidia incubated with one interruption of the moist period. The average number of germ tubes per germinated conidium was 1.1 after $8 \mathrm{~h}$ and increased to 1.5 after $24 \mathrm{~h}$ when conidia were incubated under continuously moist conditions. When a dry period started after $8 \mathrm{~h}$ of incubation under moist conditions, the number of germ tubes was 1.3. After a total of $32 \mathrm{~h}$ of moist incubation, 1.3 germ tubes were observed per germinated conidium. The majority of germ tubes were shorter than $50 \mu \mathrm{m}$ after an incubation period of $8 \mathrm{~h}$ for both treatments. When conidia of both treatments had been incubated for 24 or $32 \mathrm{~h}$, respectively, under moist conditions, the majority of the first germ tubes was longer than $250 \mu \mathrm{m}$ and the distribution of germ tube lengths had the same pattern for both treatments (data not shown). Also, the distribution of the length of second germ tubes had the same pattern for both treatments.

In another repeated experiment, conidia on agar slides were incubated in a moist environment $(-1 \mathrm{MPa})$ and this moist incubation was interrupted two or three times by a period of dry conditions (-42 MPa). The Gompertz curves fitted well to the data with an adjusted $R^{2}$ ranging between 0.82 and 1.00 (Fig. 4). Values for germination percentages determined at the beginning of each dry period $(-42 \mathrm{MPa})$ and at the end of the dry period (data not shown) did not differ significantly, indicating that the germination process did not continue during dry periods. The estimated maximum levels for percentage germination $(C)$ tended to be lower, with 71 and $77 \%$ for conidia which were incubated with two or three dry periods $(-42 \mathrm{MPa})$ as compared with the control treatment with continuously moist incubation (87\%) (Table 4). However, these differences were not significant $(P=0.103)$. The slope parameters $(B)$ and the point of inflection $(M)$ for the control treatment differed statistically significantly from treatments with two or three dry periods, showing that conidial germination was slower after multiple interruptions of the germination process. It can be calculated from the fitted curves that a germination percentage of $50 \%$ was reached under continuously moist incubation after $8.7 \mathrm{~h}$. When moist conditions were interrupted two or three times, 16.2 and $21.1 \mathrm{~h}$ of moist incubation were needed, respectively. The germination process was thus retarded by approximately $4 \mathrm{~h}$ per interruption of the moist period.

In this experiment, germinated conidia had 1.6 germ tubes when maximum germination was reached after $24 \mathrm{~h}$ for conidia incubated under continuously moist conditions. For conidia incubated

TABLE 3. Parameter estimates of Gompertz curves fitted to the germination percentage of conidia of Ulocladium atrum incubated on agar slides under moist conditions $(-1 \mathrm{MPa})$ interrupted by a dry period at $-42 \mathrm{MPa}$ during the initial stage of germination

\begin{tabular}{|c|c|c|c|}
\hline \multirow[b]{2}{*}{ Duration $(\mathrm{h})^{\mathrm{y}}$} & \multicolumn{3}{|c|}{ Gompertz curves parameters ${ }^{\mathrm{x}}$} \\
\hline & $M$ & $B$ & $C$ \\
\hline 0 & 8.1 & 0.71 & 88 \\
\hline 2 & 9.4 & 0.54 & 90 \\
\hline 4 & 10.4 & 0.44 & 91 \\
\hline 6 & 12.4 & 0.38 & 88 \\
\hline \multicolumn{4}{|l|}{ Analysis ${ }^{z}$} \\
\hline Slope & $0.702( \pm 0.105)$ & $-0.054( \pm 0.017)$ & $0.129( \pm 0.451)$ \\
\hline$t$ probability & $<0.001$ & 0.021 & 0.785 \\
\hline
\end{tabular}

${ }^{x}$ Means of two experiments; $M=$ point of inflection, $B=$ slope parameter, and $C=$ upper asymptote.

${ }^{y}$ Duration of initial moist period; sum of moist plus dry period was $24 \mathrm{~h}$.

${ }^{z}$ Linear regression analysis between Gompertz curve parameters and duration of initial moist incubation; Slope parameter ( \pm standard error). 
with three moist-dry cycles, the number of germ tubes and germ tube length was assessed immediately after the last cycle (after a total of $18 \mathrm{~h}$ of moist incubation) and after a total of $42 \mathrm{~h}$ of moist incubation. Germinated conidia had 1.2 and 1.4 germ tubes after 18 and $42 \mathrm{~h}$ of total moist incubation. The germ tube length for germinated conidia after a total of $18 \mathrm{~h}$ of moist incubation was below $50 \mu \mathrm{m}$ for the majority of the conidia. After a total of $42 \mathrm{~h}$ of moist incubation, germ tubes length was $>250 \mu \mathrm{m}$ for the majority of the conidia.

Antagonism on cyclamen leaves at different water-potentials. The sporulation intensity of $B$. cinerea decreased with water potential but sporulation was also found on leaves treated with the higher dose of $B$. cinerea and incubated at $-7 \mathrm{MPa}$ (Table 5). Significant interactions between treatment and water potential occurred. The sporulation of $B$. cinerea was significantly reduced by $U$. atrum at all water potentials, except for leaves inoculated with the low dose of $B$. cinerea and incubated at $-7 \mathrm{MPa}$, which showed only sparse sporulation of the pathogen. Similar results were obtained in both replicate experiments.

\section{DISCUSSION}

Little information is available in the literature about the fate of germlings of saprophytic fungi in the phyllosphere. More information is published on leaf pathogens which are exposed to periods of low water availability. However, in contrast to saprophytes, once the moist period is long enough for infection, pathogens may escape such adverse microclimatic conditions by penetrating host tissue. Bashi and Rotem (2) showed that pathogens developed different survival strategies under semi-arid conditions. Phytophthora infestans rapidly penetrates host leaves to escape from dry conditions; Stemphylium botryosum f. sp. lycopersici produces drought-resistant germ tubes. High drought resistance of germlings is also reported for other fungal leaf pathogens. The majority of germinated conidia of Venturia inaequalis survived on apple leaves during dry periods, but survival was reduced compared with ungerminated conidia (3). Germlings of Cercospora kikuchii, causing leaf blight in soybean (27), Botrytis cinerea, Cercospora musae, and Monilinia fructicola survived dry periods (11). In contrast, germlings of Botryosphaeria obtusa, causing leaf spot in apple, were extremely sensitive to interruptions of leaf wetness and did not resume growth (1). Also, germinated pycnidiospores of Mycosphaerella pinodes were found to be sensitive to inter-

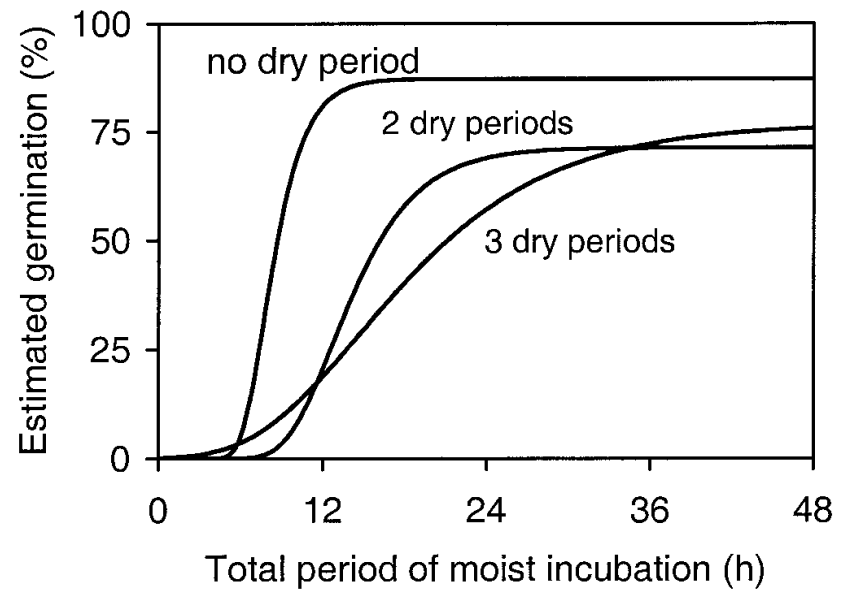

Fig. 4. Estimated germination percentage of conidia of Ulocladium atrum continuously incubated on agar slides under moist conditions $(-1 \mathrm{MPa})$ or incubated with two or three moist-dry cycles $(6 \mathrm{~h}$ at $-1 \mathrm{MPa}$ and $18 \mathrm{~h}$ at $-42 \mathrm{~h}$ ) at the beginning of the experiment followed by continuously moist incubation. Gompertz curves were fitted to data obtained from repeated experiments. Adjusted $R^{2}$ for the different treatments ranged between 0.82 and 1.00 for the different treatments. ruption of leaf wetness period before appressorium formation on pea leaves (25).

Survival of germlings during dry periods can differ for dematiaceous and hyaline fungi (8). A high percentage of germlings of dematiaceous fungi such as Alternaria tenuis, S. botryosum, Helminthosporium sativum, and Cladosporium herbarum survived dry periods (8), but germlings of hyaline species such as Aspergillus, Penicillium, and Colletotrichum graminicola died during dry periods. Park (22) compared the time fungal hyphal tips needed for regrowth after dry periods. Phyllosphere inhabitants such as A. alternata, Aureobasidium pullulans, B. cinerea, Cladosporium cladosporioides, and Epicoccum purpurascens initiated hyphal tip growth within 60 min of moist incubation. Hyphal tips of soil fungi such as Fusarium solani, Gliocladium roseum, Humicola grisea, and Trichoderma harzianum and storage fungi such as Penicillium spp. were all nonviable after a dry period. Park (22) found that phylloplane fungi cannot grow at water potential below $-15 \mathrm{MPa}$ but survive under such conditions. Nonphylloplane fungi can be seriously affected by such low water potentials. L. Hjeljord and A. Tronsmo (personal communication) found that conidia of $T$. harzianum were killed when exposed to desiccation during germination.

It is known from earlier studies that $U$. atrum survives and successfully competes with Botrytris spp. on necrotic leaves after interruptions of leaf wetness periods under controlled conditions (18) and in the field (17). However, the effect of interruptions of wetness periods on the development of germ tubes and the effect of low water potentials on conidial germination and competitive colonization of necrotic leaves with Botrytis spp. has not been studied before. Water potential relationships in fungi can be studied on artificial media in which the osmotic or matric conditions are altered by adding salts, glycerol, or polyethylene glycol. Direct effects of these additions on fungal metabolism cannot be excluded and may explain the interactions often found between water potential and additives when fungal development is quantified $(19,20)$. To avoid such interactions, methods were applied in

TABLE 4. Parameter estimates of Gompertz curves fitted to the germination percentage of conidia of Ulocladium atrum incubated on agar slides under moist conditions $(-1 \mathrm{MPa})$ interrupted by two or three dry periods $(-42 \mathrm{MPa})$ during the initial stage of germination

\begin{tabular}{lccc}
\hline & \multicolumn{3}{c}{ Gompertz curves parameters $^{\mathrm{y}}$} \\
\cline { 2 - 4 } Interruption $^{\mathrm{z}}$ & $M$ & $B$ & $C$ \\
\hline 0 dry periods & 7.7 & 0.61 & 87 \\
2 dry periods & 12.7 & 0.30 & 71 \\
3 dry periods & 14.6 & 0.13 & 77 \\
LSD $(\alpha=0.05)$ & 2.6 & 0.24 & 15 \\
$F_{\text {prob. }}$ & $<0.001$ & 0.004 & 0.103 \\
\hline
\end{tabular}

${ }^{y}$ Means of two experiments; $M=$ point of inflection, $B=$ slope parameter, and $C=$ upper asymptote.

${ }^{\mathrm{z}}$ Interruption of initial moist incubation. During each moist-dry cycle, conidia were incubated for $8 \mathrm{~h}$ at $-1 \mathrm{MPa}$ followed by $18 \mathrm{~h}$ at $-42 \mathrm{MPa}$. LSD $=$ least significant difference.

TABLE 5. Effect of Ulocladium atrum on the sporulation of Botrytis cinerea on cyclamen leaves at different water potentials (MPa)

\begin{tabular}{lrcc}
\hline & \multicolumn{3}{c}{ Sporulation index $(0-100)^{\mathrm{y}}$} \\
\cline { 2 - 4 } Treatment $^{\mathrm{z}}$ & $-1 \mathrm{MPa}$ & $-3 \mathrm{MPa}$ & $-7 \mathrm{MPa}$ \\
\hline B. cinerea $10^{5}$ & $17.2 \mathrm{a}$ & $4.6 \mathrm{a}$ & $0.05 \mathrm{~b}$ \\
B. cinerea $10^{5}+U$. atrum & $0.4 \mathrm{c}$ & $0.1 \mathrm{c}$ & $0.00 \mathrm{~b}$ \\
B. cinerea $10^{6}$ & $15.3 \mathrm{a}$ & $6.1 \mathrm{a}$ & $0.63 \mathrm{a}$ \\
B. cinerea $10^{6}+U$. atrum & $3.0 \mathrm{~b}$ & $1.0 \mathrm{~b}$ & $0.01 \mathrm{~b}$ \\
\hline
\end{tabular}

y Backtransformed means of two experiments. Values within a column followed by the same letter do not differ significantly (least significant difference-test after angular transformation; $\alpha=0.05$ ).

${ }^{\mathrm{z}} B$. cinerea was applied at $10^{5}$ or $10^{6}$ conidia per $\mathrm{ml}$ and $U$. atrum was applied at $10^{6}$ conidia per $\mathrm{ml}$. 
the present study to control the water potential of a thin water agar layer via equilibrium with the $\mathrm{RH}$ of the air, which was controlled by media with adjusted water potential, but separated from the fungal growth medium (24).

When conidia of $U$. atrum were incubated on water agar slides, the speed of germination and the estimated maximum germination (upper asymptote $C$ ) decreased with decreasing water potential. Endogenous nutrients play a crucial role during germination under water stress and the establishment of the antagonist Epicoccum nigrum after application in the field (23). Conidia of the U. atrum inoculum used in the present study may contain different amounts of endogenous nutrients, possibly accumulated during maturation. As a consequence, the fraction of conidia with low nutrient level may remain ungerminated under stress conditions.

Germinating conidia were not killed when humid incubation was interrupted by one dry period and the maximum germination percentage $(C)$ was the same for conidia incubated with or without an interruption of moist conditions. Significant differences were found for the time needed to reach $37 \%$ of the level of the maximum germination percentage (point of inflection $M$ ). After incubation at $-10 \mathrm{MPa}$, conidia and germ tubes needed 1.6 to $2.3 \mathrm{~h}$ longer to take up water again from the surrounding humid air and to start regrowth when they were first incubated under moist conditions for 2 to $8 \mathrm{~h}$, as compared to the control conidia incubated without interruption of the moist period. Thereafter, the speed of the germination process (slope parameter $B$ ) did not differ statistically significantly between treatments. Conidia incubated first at $-42 \mathrm{MPa}$ needed longer to start regrowth. The delay for conidia which had an initial moist incubation was 1.3 to $4.3 \mathrm{~h}$ longer as compared to conidia incubated without interruption of the moist period. The speed of germination tended to be slower with longer initial incubation period under moist conditions. Conidia initially incubated for 4 to $6 \mathrm{~h}$ under moist conditions needed longer periods to continue with germination than conidia incubated initially for 2 or $8 \mathrm{~h}$ under moist conditions. It can be concluded that pregerminated conidia of $U$. atrum survive a dry period but continue the germination process at lower speed after such a dry period. The most vulnerable stage is reached after an initial moist incubation period at $18^{\circ} \mathrm{C}$ of 4 to $6 \mathrm{~h}$, when germination percentage was 0 to $10 \%$ and germ tubes were shorter than $20 \mu \mathrm{m}$. Conidia were more stressed when incubated with two or three moist-dry cycles, resulting in a slower germination process as compared with conidia incubated with or without a single dry interruption of moisture. However, germinated conidia survived the repeated moistdry cycles and reached the same high maximum germination percentage as conidia incubated without a moist-dry cycle.

Conidia incubated without or with one or three moist-dry cycles had the same number of germ tubes. After moist incubation following dry periods, germ tube length significantly increased as compared with their length before dry periods, which indicates that conidia of $U$. atrum do not produce new germ tubes after dry periods but that the existing germ tubes already formed during the initial humid period continued growth. In contrast to our results, renewed germination was found by Dickinson (7) for Alternaria alternata, a fungus closely related to $U$. atrum. Our attempts to follow viability and growth of individual germ tubes more directly failed. Techniques using vital stains such as fluoresceine diacetate (FDA) were not reliable because germ tubes showed no reaction directly after a dry period but the same germ tubes were stained after several hours of moist incubation. A reliable differentiation between living and dead germ tubes during dry periods was not possible. Attempts were also made to measure the speed of hyphal tip growth by following individual germ tubes in time during and after dry periods. Therefore, videomicroscopy combined with automated image analysis was used. However, germ tubes rapidly grew out of focus and germ-tube length could not be measured.

To study the antagonism of $U$. atrum against $B$. cinerea at different water potentials, a method was developed which guaranteed a constantly controlled water potential of the substrate. Conidia were applied to glass slides in water suspensions which were allowed to evaporate before the conidia came into contact with the necrotic leaves with adjusted water potentials; hence, the water potential of the leaves was not changed. These results show that $U$. atrum can successfully compete with $B$. cinerea not only under conditions of optimum water availability but also when water availability is suboptimal.

This study on the effect of moist-dry cycles on germinating conidia of $U$. atrum and the effect of different constant water potentials on conidial germination and antagonism against $B$. cine$r e a$, together with earlier studies $(17,18)$, demonstrates that $U$. atrum tolerates water stress and thus, with respect to this attribute, is adapted to the ecological niche of leaf surfaces and aboveground necrotic tissues. These results help us to understand the fate of conidial inoculum of the antagonist after field applications. Based on this knowledge of the ecological competence of the antagonist, application frequencies and densities can be optimized to achieve sufficiently high population densities of the antagonist on the target substrates with economically sound dosages.

\section{ACKNOWLEDGMENTS}

Funding of this study was provided by the EC (FAIR3 CT96-1898 BIOSPORSUPPRESS), the Dutch Product Board for Horticulture, and the Dutch Ministry of Agriculture, Nature Management, and Fisheries. We thank N. J. Fokkema (IPO) and N. Magan (Cranfield University, UK) for stimulating discussions, and S. L. G. E. Burgers and E. A. M. van Remortel for statistical analysis.

\section{LITERATURE CITED}

1. Auruz, L. F., and Sutton, T. B. 1990. Effect of interrupted wetness periods on spore germination and apple infection by Botryosphaeria obtusa. Phytopathology 80:1218-1220.

2. Bashi, E., and Rotem, J. 1974. Adaptation of four pathogens to semi-arid habitats as conditioned by penetration rate and germinating spore survival. Phytopathology 64:1035-1039.

3. Becker, C. M., and Burr, T. J. 1994. Discontinuous wetting and survival of conidia of Venturia inaequalis on apple leaves. Phytopathology 84:372-378.

4. Braun, P. G., and Sutton, J. C. 1988. Infection cycles and population dynamics of Botrytis cinerea in strawberry leaves. Can. J. Plant Pathol. 10:133-141.

5. Campbell, G. S., and Gardner, G. A. 1971. Psychometric measurement of soil water potential: Temperature and bulk density effects. Proc. Soil Sci. Soc. Am. 35:8-12.

6. Dallyn, H., and Fox, A. 1980. Spoilage of Material of Reduced Water Activity by Xerophylic Fungi. G. H. Gould and J. E. L. Corry, eds. Blackwell Scientific Publications, Oxford, UK.

7. Dickinson, C. H. 1981. Biology of Alternaria alternata, Cladosporium cladosporioides and $C$. herbarum in respect of their activity on green plants. Pages 169-184 in: Microbial Ecology of the Phylloplane. J. P. Blakeman, ed. Academic Press, London.

8. Diem, H. G. 1971. Effect of low humidity on the survival of germinated spores commonly found in the phyllosphere. Pages 211-219 in: Ecology of Leaf Surface Micro-Organisms. T. F. Preece and C. H. Dickinson, eds. Academic Press, London.

9. Fokkema, N. J. 1984. Competition for endogenous and exogenous nutrients between Sporobolomyces roseus and Cochliobolus sativus. Can. J. Bot. 62:2463-2468.

10. Fruit, L., and Nicot, P. 1999. Biological control of Botrytis cinerea on tomato stem wounds with Ulocladium atrum. IOBC Bull. 22:81-84.

11. Good, H. M., and Zathureczky, P. G. M. 1967. Effects of drying on the viability of germinated spores of Botrytis cinerea, Cercospora musae, and Monilinia fructicola. Phytopathology 57:719-722.

12. Jarvis, W. J. 1962. The infection of strawberry and raspberry fruits by Botrytis cinerea Fr. Ann. Appl. Biol. 50:569-575.

13. Köhl, J., and Fokkema, N. J. 1998. Biological control of Botrytis cinerea by suppression of sporulation. Pages 681-686 in: Proc. Brighton Crop Prot. Conf. Pests Dis., Crop Prot. Counc., Farnham, UK.

14. Köhl, J., Gerlagh, M., De Haas, B. H., and Krijger, M. C. 1998. Biological control of Botrytis cinerea in cyclamen with Ulocladium atrum and Gliocladium roseum under commercial growing conditions. Phytopa- 
thology 88:568-575

15. Köhl, J., Krijger, M. C., and Kessel, G. J. T. 1992. Drought tolerance of Botrytis squamosa, B. aclada and potential antagonist. Pages 206-210 in: Recent Advances in Botrytis Research. K. Verhoeff, N. E. Malathrakis, and W. Williamson, eds. Pudoc Scientific Publishers, Wageningen, the Netherlands.

16. Köhl, J., Lombaers-van der Plas, C. H., Molhoek, W. M. L., Kessel G. J., and Goossen-van der Geijn, H. J. 1999. Competitive ability of the antagonist Ulocladium atrum and Gliocladium roseum at temperatures favourable for Botrytis spp. development. BioControl 44:329-346.

17. Köhl, J., Molhoek, W. M. L., van der Plas, C. H., and Fokkema, N. J. 1995. Effect of Ulocladium atrum and other antagonists on sporulation of Botrytis cinerea on dead lily leaves exposed to field conditions. Phytopathology 85:393-401.

18. Köhl, J., van der Plas, C. H., Molhoek, W. M. L., and Fokkema, N. J. 1995. Selection of antagonists suppressing sporulation of Botrytis allii and $B$. cinerea after interrupted wetness periods. Eur. J. Plant Pathol. 101:627-637.

19. Magan, N. 1988. Effects of water potential and temperature on spore germination and germ-tube growth in vitro and in straw leaf sheaths. Trans. Br. Mycol. Soc. 90:97-107.

20. Magan, N., and Lynch, J. M. 1986. Water potential, growth and cellulolysis of fungi involved in decomposition of cereal residues. J. Gen. Microbiol. 132:1181-1187.
21. Mead, R. 1988. The Design of Experiments. Cambridge University Press, Cambridge, U.K.

22. Park, D. 1982. Phylloplane fungi: Tolerance of hyphal tips to drying. Trans. Br. Mycol. Soc. 79:174-178

23. Pascual, S., Magan, N., and Melgarejo, P. 1996. Improved biological control of peach twig blight by physiological manipulation of Epicoccum nigrum. Pages 411-412 in: Proc. Brighton Crop Prot. Conf. Pests Dis., Crop Prot. Counc., Farnham, UK.

24. Pfender, W. F., Sharma, U., and Zhang, W. 1991. Effect of water potential on microbial antagonism to Pyrenophora tritici-repentis in wheat residue. Mycol. Res. 95:308-314.

25. Roger, C., Tivoli, B., and Huber, L. 1999. Effects of interrupted wet periods and different temperatures on the development of Ascochyta blight caused by Mycosphaerella pinodes on pea (Pisum sativum) seedlings. Plant Pathol. 48:10-18.

26. Schoene, P., and Köhl, J. 1999. Biologische Bekämpfung von Botrytis cinerea mit Ulocladium atrum in Reben und Cyclamen. Gesunde Pflanz. 51:81-85.

27. Schuh, W. 1993. Influence of interrupted dew periods, relative humidity, and light on disease severity and latent infections caused by Cercospora kikuchii on soybean. Phytopathology 83:109-113.

28. Wolf, T. K., Baudoin, A. B. A. M., and Martinez-Ochoa, N. 1997. Effect of floral debris removal from fruit clusters on Botrytis bunch rot of Chardonnay grapes. Vitis 36:27-33. 